\title{
Bendamustine in Patients with Relapsed or Refractory Multiple Myeloma
}

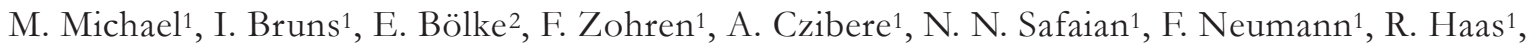 \\ G. Kobbe ${ }^{1}$, R. Fenk ${ }^{1}$ \\ ${ }^{1}$ Department of Hematology, Oncology and Clinical Immunology, ${ }^{2}$ Department of Radiooncology, \\ Heinrich-Heine-University, Duesseldorf, Germany
}

\begin{abstract}
Objective: In patients with multiple myeloma, bendamustine monotherapy is effective as $1^{\text {st }}$ and $2^{\text {nd }}$ line therapy. However, data for patients with advanced multiple myeloma is rare.

Methods: In this retrospective analysis we have identified 39 patients with relapsed or refractory multiple myeloma by means of case research, who have been treated at our institution with bendamustine as salvage therapy. After in median 2 lines of prior therapy (range:1-5) patients received in median 3 (range: $1-10$ ) cycles of bendamustine. Bendamustine dosage was $80-$ $150 \mathrm{mg}$ on day $1+2$ of a monthly cycle. Bendamustine was administered as monotherapy in 39\% of patients, whereas $61 \%$ received concomitant steroids.

Results: Toxicity was mild to moderate. Response rates were as follows: 3\% vgPR, 33\% PR, 18\% MR, 26\% $\mathrm{SD}$ and $20 \%$ PD. The median event-free and overall survival were 7 and 17 months, respectively.

Conclusions: In conclusion, in patients with advanced multiple myeloma bendamustine is effective and associated with mild toxicity. Therefore, the role of bendamustine in patients with multiple myeloma should be investigated in further clinical trials.
\end{abstract}

Key words: Bendamustine, multiple myeloma, relapsed/ refractory

\section{INTRODUCTION}

High-dose chemotherapy followed by autologous peripheral blood stem cell transplantation (PBSCT) has improved response rates and survival in patients with multiple myeloma $[1,2]$. Despite further dose escalation, almost all patients ultimately suffer from disease progression [3, 4]. Therefore, there is a continuous need to broaden the spectrum of salvage therapies for those patients [5]. In addition to novel agents such as thalidomide [6], lenalidomide [7] and bortezomib [8], conventional cytotoxic chemotherapy remains a treatment option in this situation. In this respect one may consider bendamustine, which is a bifunctional alkylating agent. It is characterised by a unique profile of cytotoxicity and there is only partial cross-resistance with other alkylating agents or anthracyclines [9, 10; 12]. Bendamustine is used for the treatment of non-Hodgkin-lymphoma and chronic lymphatic leu- caemia, but also for therapy of lung and breast cancer [10-19].

In myeloma cells, bendamustine induces a G2 cell cycle arrest and p53-mediated apoptosis [20]. In patients with multiple myeloma, efficacy has been reported as a single-agent as well as in combination with other agents, while the toxicity observed was mild and mainly haematological [21-26]. Poenisch et al. randomized patients with newly diagnosed multiple myeloma to either a bendamustine/prednisone regimen or standard melphalan/prednisone. The overall response rate (minimal response $(\mathrm{MR})+$ partial response $(\mathrm{PR})+$ complete response (CR)) was the same with both regimen, but the treatment with bendamustine led to an increased CR rate $(32 \%$ vs. $13 \%, \mathrm{p}=0.007)$. The duration of remission in patients with $\mathrm{CR}$ or PR was also significantly longer (18 months vs. 12 months, p < 0.02 ), while the median overall survival (OS) was not significantly different (32 vs. 33 months). Still, the quality of life was better in the group of patients who received bendamustine [23].

In patients with first relapse after high dose therapy and autologous PBSCT, Knop et al. observed an overall response rate of $55 \%$ with bendamustine as salvage therapy. In this study a median event-free survival (EFS) of six months was observed [24]. In combination with prednisolone and thalidomide bendamustine resulted in response rates of $80 \%$ in patients with relapsed and refractory multiple myeloma [25]. In another trial patients not responding to a bortezomib/dexamethasone regimen received a triple therapy consisting of bortezomib, dexamethasone and bendamustine, which resulted in a 57\% response rate [26], another study reports an overall response rate of $88 \%$ in this combination [27].

In conclusion, there is evidence that bendamustine is effective in different stages of multiple myeloma. However, there is no data for bendamustine monotherapy in patients with advanced disease. Therefore, we report on 39 patients in this situation.

\section{Material, Methods and Statistics}

\subsection{Patients}

We conducted a retrospective analysis of patients with advanced multiple myeloma who have been treated with bendamustine at our institution between April 
2000 and May 2005. Based on the institutional pharmacy records we identified patients with multiple myeloma who have been treated with bendamustine. As concomitent treatment, only steroids and radiation therapy were allowed. Exclusion criteria for this retrospective analysis were treatment with other combination partners, dosage of less than $80 \mathrm{mg} / \mathrm{m}^{2}$, prior bendamustine treatment, first-line treatment or missing data concerning remission rate and event-free survival. Clinical data of patients included in the analysis was obtained by the means of case research. Bendamustine was approved for treatment of myeloma patients in Germany and all patients gave written informed consent for treatment with bendamustine.

\subsection{Treatment Schedule}

Bendamustine hydrochloride was administered intravenously at a dose of $80-150 \mathrm{mg} / \mathrm{m}^{2}$ in $500 \mathrm{ml} \mathrm{NaCl}$ $0.9 \%$ over 30 minutes on day $1+2$. The dose was assessed by the physician according to the health state and the comorbidity of the patient. Corticosteroids were chosen as concomitant treatment according to the treating physicians decision, without any detectable pattern for decision making. The steroids used were either prednisolone $100 \mathrm{mg}$ on day 1-5 or dexamethasone $40 \mathrm{mg}$ on day $1+2$. Cycles were repeated in median after 28 days (range: 14-90 days). Growth factors and antibiotic prophylaxis were not used. Treatment was continued until either induction of remission $(\geq \mathrm{PR})$ or disease progression occurred.

\subsection{Statistical Methods}

Treatment response and duration of remission were assessed according to the EBMT criteria [28]. The EFS was calculated for all patients, who achieved at least a minimal response, from the date of first bendamustine treatment to the time of disease progression, relapse or death. OS was calculated from the date of starting bendamustine treatment to the date of death. Kaplan-Meier curves for EFS and OS were plotted and compared with the use of the log-rank test. Adverse events were assessed as documented in patients records according to CTC AE criteria version 3.0. The two-sided Fisher exact test was used to compare the response rates or the number of adverse events. Prognostic factors were determined by univariate analysis and the use of the log rank test. The following parameters were included in the univariate analysis: age $(</>65$ years), refractory (not achieving at least stable disease by last treatment line) or relapsed (progressive disease after achieving at least stable disease by last treatment line) disease, monotherapy versus concomitant steroids, bendamustine dose (80-100 or $120-150 \mathrm{mg} / \mathrm{m}^{2}$ ), prior thalidomide or prior high-dose therapy and autologous stem cell transplantation (yes or no), extramedullary manifestation (yes or no), cytogenetic abnormalities (karyotype normal versus abnormal), osteolytic lesions (yes or no), ISS stage (I vs. II/III), LDH $(</>200$ $\mathrm{U} / \mathrm{l})$, CRP $(</>0.6 \mathrm{mg} / \mathrm{dl})$, haemoglobine level $(</>10 \mathrm{~g} / \mathrm{dl})$, platelet count $(</>200.000 / \mu \mathrm{l})$, hypercalciaemia $(</>2.6 \mathrm{mmol} / \mathrm{l})$, elevated creatinine
$(</>1.2 \mathrm{mg} / \mathrm{dl})$. SSPS V14.1 was used for statistical analysis.

\section{Results}

\subsection{Patient Characteristics}

Using pharmacy records we could identify 75 patients with multiple myeloma who received bendamustine treatment in our institution. Of all, 39 patients entered the retrospective analysis. Reasons for exclusion from the analysis were insufficient data $(n=19)$, combination partners other than steroids $(n=10)$, firstline treatment $(n=5)$, total bendamustine dosage of less than $80 \mathrm{mg} / \mathrm{m}^{2}(\mathrm{n}=2)$. The patients in our study had an advanced stage of disease as reflected by a median of two lines of prior treatment regimen (range: 1-5). This includes high-dose therapy and autologous PBSCT in $64 \%$ of the patients and a second highdose therapy as salvage treatment in 23\%. Prior thalidomide treatment had been administed in $59 \%$ of the patients. Of all patients, 54\% were refractory to the last salvage therapy, whereas $46 \%$ suffered from progressive disease after a remission or stable disease had been achieved by the antecedent therapy. About one third of patients presented with extramedullary manifestations (28\%). Patient characteristics before the begin of bendamustine treatment are shown in Table 1.

\subsection{Treatment Profile}

Patients received a median of 3 (range 1-10) cycles of bendamustine. Of all, 25 patients $(64 \%)$ received bendamustine treatment until disease progression. These patients were treated with in median 4 cycles (1-10). In 13 patients $(33 \%)$ bendamustine treatment was stopped after in median 3 cycles (1-9) during ongoing remission.

The median dose was $100 \mathrm{mg} / \mathrm{m}^{2}$ (range 80-150 $\mathrm{mg} / \mathrm{m}^{2}$ ) on day $1+2$. For our evaluation the patients were retrospectively allocated to two different groups according to the administered dose of $80-100 \mathrm{mg} / \mathrm{m}^{2}$ ( $\mathrm{n}=20$ ) versus $120-150 \mathrm{mg} / \mathrm{m}^{2}(\mathrm{n}=19)$.

Dose reduction was necessary in $28 \%(n=11)$ of the patients because of haematological side effects, while a discontinuation was not neccessary for any of the patients. $31 \%$ of the patients received bendamustine monotherapy and 69\% received bendamustine in combination with corticosteroids.

\subsection{RESPONSE RATES}

The overall response rate $(\mathrm{CR}+\mathrm{PR})$ was 36\% (Table $2)$. No CR was observed. In one case $(3 \%)$, a very good PR could be achieved while 13 patients entered into a PR (33\%). A MR was observed in 7 patients $(18 \%)$, whereas stable and progressive disease were noted in $10(26 \%)$ and $8(20 \%)$ patients, respectively.

Subgroup analysis showed no significant differences in outcome in relation to the dose of bendamustine administered (Table 2). Within the subgroup of patients who had received a dose of $80-100 \mathrm{mg} / \mathrm{m}^{2}$, the rate of PR was 33\% compared with $38 \%$ in the group 


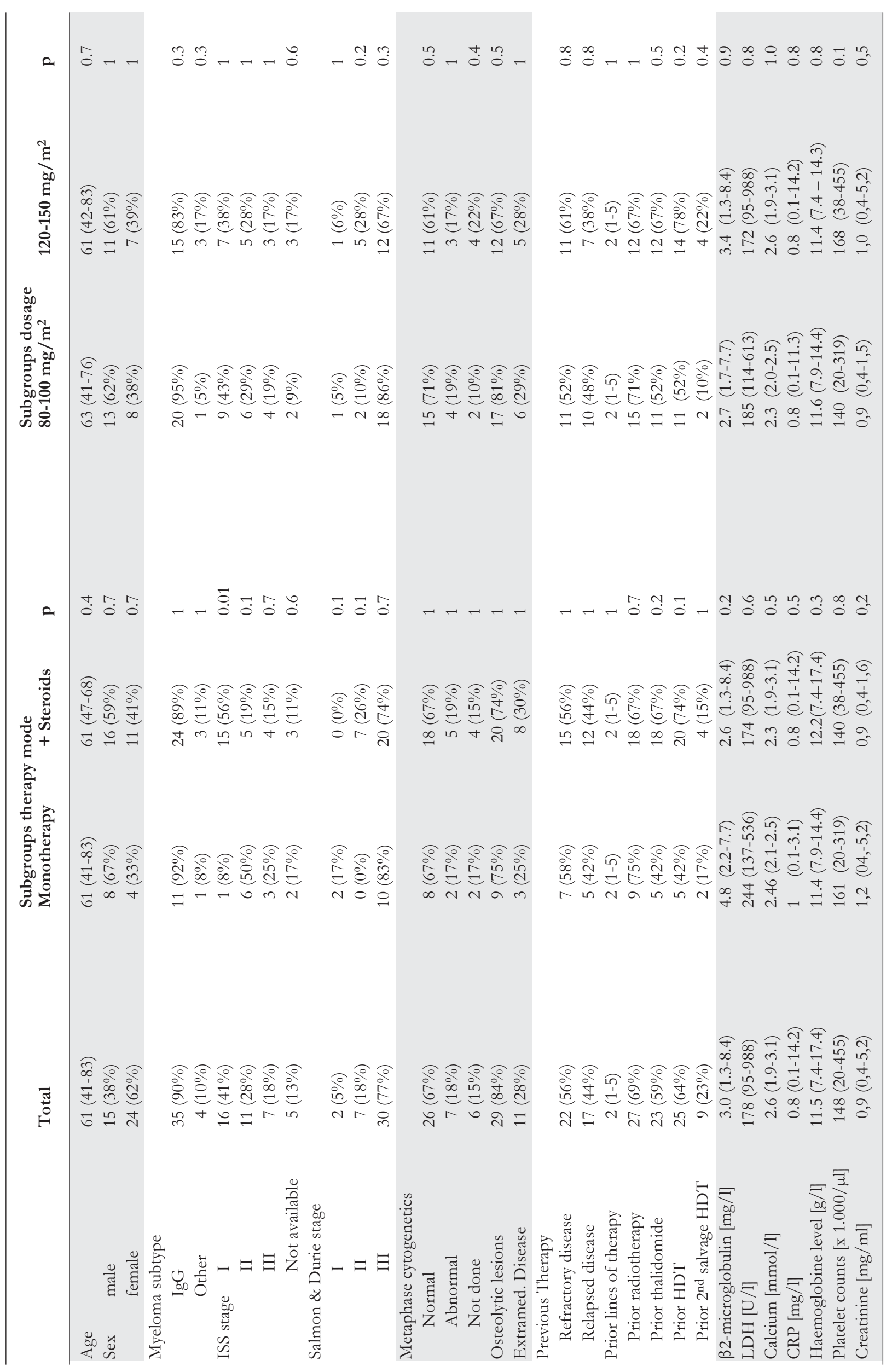


Table 2. Response rates \& subgroup analysis.

\begin{tabular}{|c|c|c|c|c|c|c|c|c|c|c|c|c|}
\hline \multirow{2}{*}{\multicolumn{3}{|c|}{$\mathrm{n}=39$}} & \multicolumn{5}{|c|}{ Subgroups dosage } & \multicolumn{5}{|c|}{ Subgroups therapy mode } \\
\hline & & & \multicolumn{2}{|c|}{$\begin{array}{l}80-100 \mathrm{mg} / \mathrm{m}^{2} \\
\mathrm{n}=21\end{array}$} & \multicolumn{2}{|c|}{$\begin{array}{l}120-150 \mathrm{mg} / \mathrm{m}^{2} \\
\mathrm{n}=18\end{array}$} & \multirow{2}{*}{$\frac{p}{0.8}$} & \multicolumn{2}{|c|}{$\begin{array}{l}\text { Monotherapy } \\
\mathrm{n}=12\end{array}$} & \multicolumn{2}{|c|}{$\begin{array}{l}+ \text { Steroids } \\
\mathrm{n}=27\end{array}$} & \multirow{2}{*}{$\frac{\mathrm{p}}{0.5}$} \\
\hline PR & $14(1 \mathrm{vgPR})$ & $36 \%$ & 7 & $33 \%$ & 7 & $38 \%$ & & 3 & $25 \%$ & 11 & $40 \%$ & \\
\hline MR & 7 & $18 \%$ & 4 & $19 \%$ & 3 & $17 \%$ & 1.0 & 2 & $17 \%$ & 5 & $19 \%$ & 1.0 \\
\hline SD & 10 & $26 \%$ & 7 & $33 \%$ & 3 & $17 \%$ & 0.3 & 5 & $42 \%$ & 5 & $19 \%$ & 0.2 \\
\hline PD & 8 & $20 \%$ & 3 & $15 \%$ & 5 & $28 \%$ & 0.4 & 2 & $17 \%$ & 6 & $22 \%$ & 1.0 \\
\hline
\end{tabular}

vgPR very good partial remission; PR partial remission; MR Minor remission; SD stable disease; PD progressive disease

of patients who had received $120-150 \mathrm{mg} / \mathrm{m}^{2}$ ( $\mathrm{p}=$ 0.75).

In the same way, bendamustine monotherapy resulted in a PR rate of $25 \%$, which was not statistically different from combination therapy of bendamustine with corticosteroids $(40 \%, \mathrm{p}=0.48$, Table 2$)$.

Table 3. Univariate analysis.

\begin{tabular}{lll}
\hline & EFS & OS \\
\hline ISS stage $(\mathrm{I}$ vs. II+II) & 0.2 & 0.001 \\
Cytogenetics (normal vs. abnormal karyotype) & 0.05 & 0.2 \\
$\mathrm{LDH}(</>200 \mathrm{U} / \mathrm{l})$ & 0.5 & 0.02 \\
$\mathrm{CRP}(</>0.6 \mathrm{mg} / \mathrm{dl})$ & 0.7 & 0.001 \\
Haemoglobine level $(</>10 \mathrm{~g} / \mathrm{dl})$ & 0.2 & 0.04 \\
Platelet count $(</>200.000 / \mu \mathrm{l})$ & 0.6 & 0.1 \\
Chemosensitivity (relapse vs. refractory) & 0.4 & 0.01 \\
Prior thalidomide & 0.4 & 1.0 \\
Prior high-dose therapy & 0.5 & 0.4 \\
Extramedullary manifestation & 0.4 & 0.2 \\
Osteolytic lesions & 0.5 & 0.3 \\
Bendamustine dosage $</>120 \mathrm{mg} / \mathrm{m}^{2}$ & 0.6 & 0.9 \\
Monotherapy vs. Steroid combination therapy & 0.7 & 0.3 \\
& & \\
\hline
\end{tabular}

There also were no differences in terms of remission rates for patients older than 65 years or younger patients. The same was true for patients who had received a prior high-dose therapy with PBSCT or who were treated with conventional chemotherapy (data not shown).

\subsection{Event-Free and Overall Survival}

For the entire group of patients, the median EFS was 7 months and the median time of OS was 17 months (Fig. 1). The major reason for the relatively short survival time was disease progression and not toxicity.

Univariate analysis did show metaphase cytogenetics as a prognostic parameter for EFS. This was different for OS. Patients with ISS stage II or III, refractory disease, elevated LDH (> $200 \mathrm{U} / \mathrm{l})$, elevated CRP level $(>0.6 \mathrm{mg} / \mathrm{dl})$, and anaemia (haemoglobine level $<10 \mathrm{~g} / \mathrm{dl}$ ) had a significantly shorter OS time (Table $3)$.

There were no significant differences in outcome between the two subgroups receiving either bendamustine monotherapy or combination therapy with steroids. The dose of bendamustine also had no influence on the patients' outcome. There also were no statistically differences between patients older than 65

\section{Event-free survival}

Median 7 months

\section{$\%$ of patients}

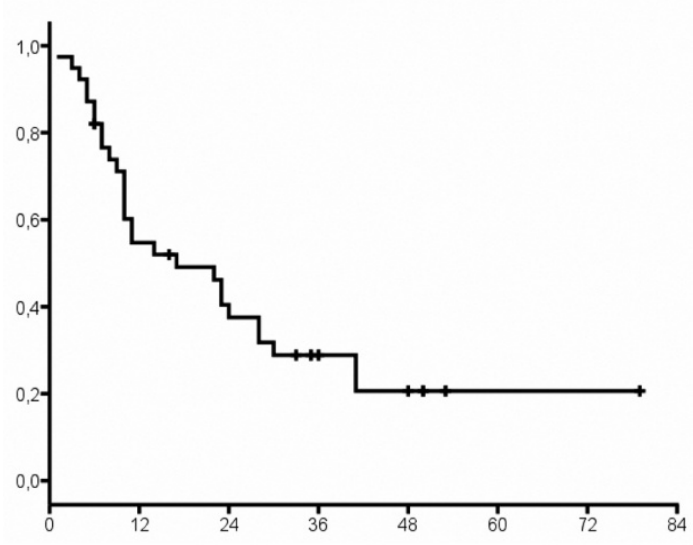

$\%$ of patients

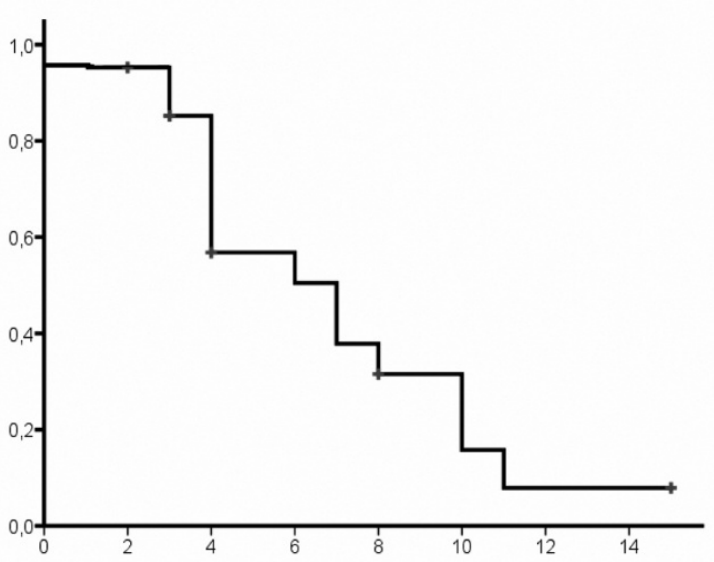

Months

Fig. 1. Overall survival of 39 patients with refractory or relapsed MM treated with bendamustine and event-free survival of 21 patients with refractory or relapsed $\mathrm{MM}$ responding $(\mathrm{MR}+\mathrm{PR}+\mathrm{CR})$ to bendamustine treatment. 
Table 4. Toxicity.

\begin{tabular}{|c|c|c|c|c|c|c|c|c|}
\hline \multirow[b]{2}{*}{ Toxicity } & & \multirow[b]{2}{*}{$\begin{array}{l}\text { All } \\
\mathrm{n}=39\end{array}$} & \multicolumn{2}{|c|}{ Subgroups therapy mode } & \multicolumn{4}{|c|}{ Subgroups dosage } \\
\hline & & & $\begin{array}{l}\text { Monotherapy } \\
\mathrm{n}=12\end{array}$ & $\begin{array}{c}+ \text { Steroids } \\
\mathrm{n}=27\end{array}$ & $\mathrm{p}$ & $\begin{array}{l}80-100 \mathrm{mg} / \mathrm{m}^{2} \\
\mathrm{n}=21\end{array}$ & $\begin{array}{l}100-120 \mathrm{mg} / \mathrm{m}^{2} \\
\mathrm{n}=18\end{array}$ & $\mathrm{p}$ \\
\hline \multirow[t]{3}{*}{ Anaemia } & ${ }^{\circ} \mathrm{I}-\mathrm{II}$ & $32(82 \%)$ & $10(84 \%)$ & $22(81 \%)$ & 1,0 & $17(81 \%)$ & $15(83 \%)$ & 1,0 \\
\hline & ${ }^{\circ}$ III-IV & $4(10 \%)$ & $1(8 \%)$ & $3(11 \%)$ & 1,0 & $3(14 \%)$ & $1(6 \%)$ & 0,6 \\
\hline & ${ }^{\circ} \mathrm{I}-\mathrm{IV}$ & $36(92 \%)$ & $11(92 \%)$ & $25(92 \%)$ & 1,0 & $20(95 \%)$ & $16(89 \%)$ & 0,6 \\
\hline \multirow[t]{3}{*}{ Neutropenia } & ${ }^{\circ} \mathrm{I}-\mathrm{II}$ & $19(49 \%)$ & $5(42 \%)$ & $14(52 \%)$ & 0,7 & $8(38 \%)$ & $11(61 \%)$ & 0,2 \\
\hline & ${ }^{\circ}$ III-IV & $16(41 \%)$ & $6(50 \%)$ & $10(37 \%)$ & 0,5 & $11(52 \%)$ & $5(28 \%)$ & 0,2 \\
\hline & ${ }^{\circ} \mathrm{I}-\mathrm{IV}$ & $35(90 \%)$ & $11(92 \%)$ & $24(89 \%)$ & 1,0 & $19(90 \%)$ & $16(89 \%)$ & 1 \\
\hline \multirow[t]{3}{*}{ Thrombopenia } & ${ }^{\circ} \mathrm{I}-\mathrm{II}$ & $18(46 \%)$ & $4(33 \%)$ & $14(52 \%)$ & 0,3 & $9(43 \%)$ & $9(50 \%)$ & 0,7 \\
\hline & ${ }^{\circ}$ III-IV & $10(26 \%)$ & $4(33 \%)$ & $6(22 \%)$ & 0,7 & $8(38 \%)$ & $2(11 \%)$ & 0,7 \\
\hline & ${ }^{\circ} \mathrm{I}-\mathrm{IV}$ & $28(72 \%)$ & $8(66 \%)$ & $20(74 \%)$ & 0,7 & $17(81 \%)$ & $11(61 \%)$ & 0,3 \\
\hline \multirow[t]{3}{*}{ Infection } & ${ }^{\circ} \mathrm{I}-\mathrm{II}$ & $3(8 \%)$ & $0(0 \%)$ & $3(11 \%)$ & 0,5 & $2(10 \%)$ & $1(6 \%)$ & 1,0 \\
\hline & ${ }^{\circ}$ III-IV & $6(15 \%)$ & $0(0 \%)$ & $6(22 \%)$ & 0,2 & $3(14 \%)$ & $3(11 \%)$ & 1,0 \\
\hline & ${ }^{\circ} \mathrm{I}-\mathrm{IV}$ & $9(23 \%)$ & $0(0 \%)$ & $9(33 \%)$ & 0,04 & $5(24 \%)$ & $4(17 \%)$ & 1,0 \\
\hline \multirow[t]{3}{*}{ Other Side Effects } & ${ }^{\circ} \mathrm{I}-\mathrm{II}$ & $12(31 \%)$ & $3(25 \%)$ & $9(33 \%)$ & 0,7 & $10(48 \%)$ & $2(11 \%)$ & 0,02 \\
\hline & ${ }^{\circ}$ III-IV & $1(3 \%)$ & $0(0 \%)$ & $1(4 \%)$ & 1,0 & $0(0 \%)$ & $1(6 \%)$ & 0,5 \\
\hline & ${ }^{\circ} \mathrm{I}-\mathrm{IV}$ & $13(33 \%)$ & $3(25 \%)$ & $10(37 \%)$ & 0,7 & $10(48 \%)$ & $3(17 \%)$ & 0,05 \\
\hline
\end{tabular}

years and younger patients or patients, which were treated with a prior PBSCT or not.

\subsection{TOXICITY}

In our study, toxicity was mild (Table 4) and consisted mainly of haematological adverse events. In $95 \%$ of the patients, haematological side effects were observed after administration of one cycle of bendamustine. In most cases (69\%) grade 1 and 2 cytopenia were observed, which did not postpone further treatment. Severe anaemia requiring red blood cell transfusions (grade 3/4) developed in 4 patients $(10 \%)$, while severe thrombocytopenia (grade 3/4) was observed in $10(26 \%)$ patients. There were $16(41 \%)$ patients with grade $3 / 4$ neutropenia and 6 of them $(15 \%)$ required iv antibiotic treatment and hospitalisation. One patient had a paravertebral abscess with spondylodiscitis requiring surgical intervention. This patient had received concomitant steroids.

Non-haematological toxicity included mainly gastrointestinal complaints. Grade 1 and 2 nausea and vomiting was observed in $8 \%(\mathrm{n}=3)$. In two patients $(5 \%)$, grade $1 / 2$ diarrhea was developed. Other grade $1 / 2$ toxicities consisted of fatigue $(n=2)$, increase of creatinine $(\mathrm{n}=3)$, paraesthesia $(\mathrm{n}=1)$ and urticaria after application of bendamustine $(\mathrm{n}=1)$. As a result, no grade 3/4 non-haematological toxicities were encountered. Alopecia was not reported for any of our patients.

There was no statistically significant difference with regard to haematologic toxicity between the different treatment groups. As far as the dose of bendamustine is concerned, there was no correlation between the dose level of bendamustine and the degree and type of toxicity. Concentrating on differences between bendamustine monotherapy and concomitant steroid therapy, haematological side effects were similar in both groups. On the other hand, infections were significant- ly more frequent in patients receiving corticosteroids (0\% vs. $33 \%, \mathrm{p}=0.04$, Table 4$)$.

There were no differences in terms of toxicity for patients older than 65 years or younger patients. In the same way patients who had received a prior high-dose therapy with autologous stem cell transplantation showed the same toxicity as patients who were treated with conventional chemotherapy.

\section{Discussion}

Bendamustine is a treatment option for patients with relapsed and refractory multiple myeloma in particular because of its low toxicity either as single agent or in combination. Herein, we present retrospective data of 39 patients with advanced multiple myeloma, showing that bendamustine is an effective agent in this treatment situation. The rate of PR was $36 \%$, which is similar to other salvage therapies. Noteworthy, in our study with a heterogeneous patient population we did not observe a better therapeutic efficacy when steroids were added. In contrast the concomitant administration of steroids was associated with a significantly higher rate of infections.

The major finding of our study is, that bendamustine is effective in patients with advanced multiple myeloma, while published data mainly focus on the role of bendamustine in early stages of the disease $[23,24]$. Salvage therapies with single agents generally results in a CR or PR in one third of patients with multiple myeloma. This also holds true for novel agents such as thalidomide [6] or bortezomib [8]. Thus, the rate of $36 \% \mathrm{PR}$, which we observed in patients with in median 2 lines of prior therapy, including $56 \%$ of patients not achieving at least SD to their last line of therapy, meets the expected overall remission rate for an effective anti-myeloma agent. However, only one vgPR and no immunofixation negative CR could be achieved. This result scales down the expec- 
tations, as quality of response, especially the achievement of CR, is considered not only a key determinant of long-term outcome for first-line therapy [29, 30], but also for salvage therapies [31-33]. The median event-free survival was seven months in our study, which is similar to salvage treatment with bortezomib, which resulted in an EFS of 6 months [8]. In comparison, salvage therapies with immunomodulatory drugs such as thalidomide and lenalidomide were associated with a longer EFS of 14 and 11 months, respectively. In summary, despite the heterogeneous patient population and the retrospective nature of our study we provide information regarding the potential efficacy of bendamustine in patients with advanced myeloma, thus expanding the therapeutic options in this treatment situation. However, our results suggest, that combination partners should be considered for bendamustine in order to further improve treatment outcome [26, 27].

Having in mind, the heterogenity of the bendamustine dosages used and the subsequent difficulties in analyzing toxicity, another interesting finding of our study was, that bendamustine was associated with relative few and mild side effects even in patients with advanced disease. As no validated questionnaire has been used $[34,35]$, it is speculative that the low toxicity is also associated with a better quality of life, as has been reported during first-line treatment [23]. However, the observed side effects in our heavily pre-treated patient population were nearly identical to the low toxicity reported for bendamustine treatment in previously untreated patients [23]. Due to this favourable toxicity profile bendamustine may be considered as promising partner for combination therapies [25-27].

Many physicians add steroids to a bendamustine treatment, because they expect a positive synergistic effect. In our study we could not find a better therapeutic efficacy of this combination either in regard to response rates, EFS or OS. At the same time patient characteristics were not significantly different between patients treated with concomitant steroids or not. In contrast, the use of steroids resulted in a higher number of infectious complications, which we did not observe with bendamustine alone. Therefore, having in mind the above mentioned caveat of our study it may be possible to omit steroids in case of recurrent infectious complications without compromising efficacy. Further prospective trials are needed to evaluate the exact role of bendumustine, its optimal dosage and best combination partners.

In conclusion, bendamustine is effective and well tolerable in patients with progressive multiple myeloma. Therefore, it is worth to further evaluate this agent in forthcoming clinical trials.

Conflict of interest: Dr. Kobbe and Dr. Fenk received research funding by Celgene and Ortho Biotech and were involved in paid consultancy.

Acknowledgement: We thank the clinical staff of the Department of Hematology, Oncology and clinical Immunology for patient care.

\section{REFERENCES}

1. Child JA, Morgan GJ, Davies FE, Owe RG, Bell SE, Hawkins $K$ et al. High-dose chemotherapy with haematopoetic stem-cell rescue for multiple myeloma. New England Journal of Medicine (2003), 348(19):18751883.

2. Attal M, Haroisseau JL. Standard therapy versus autologous transplantation in multiple myeloma. Hematology/Oncology Clinics of North America (1997), 11(1):133-146.

3. Attal M, Harousseau JL, Facon T, Guilhot F, Doyen C, Fuzibet JG et al. Single versus double autologous stemcell transplantation for multiple myeloma. New England Journal of Medicine (2003), 349(26):2495-2502.

4. Fenk R, Schneider P, Kropff M, Huenerlituerkoglu AN, Steidl U, Aul C et al. Highdose idarubicin, cyclophosphamide and melphalan as conditioning for autologous stem cell transplantation increases treatment-related mortality in patients with multiple myeloma: results of a randomised study. British Journal of Haematology (2005), 130(4):588-594.

5. Kleeberg L, Morgera S, Jacob C, Hocher B, Schneider M, Peters $\mathrm{H}$ et al. Novel renal replacement strategies for the elimination of serum free light chains in patients with kappa light chain nephropathy. European Journal of Medical Research (2009), 12(2):47-54

6. Glasmacher A, Hahn C, Hoffmann F, Naumann R, Goldschmidt H, Von Lilienfeld M, Orlopp K, Schmidt-Wolf I, Gorschlüter M. A systematic review of phase-II-trials of thalidomide monotherapy in patients with relapsed or refractory multiple myeloma. British Journal of Haematology (2005), 584-593.

7. Dimopoulos M, Spencer A, Attal M, Miles Prince H, Harousseau JL, Dmoszynska A, San Miguel J, Hellmann A, Facon T, Foa R, Corso A, Masliak Z, Olesnycky M, Yu Z, Patin J, Zeldis JB, Knight RD. Lenalidomide plus Dexamethasone for relapsed or refractory multiple myeloma. New England Journal of Medicine (2007), 357(2):2123-2132.

8. Richardson PG, Sonneveld P, Schuster MW, Irwin D, Stadtmauer EA, Facon T et al. Bortezomib in relapsed, refractory myeloma. New England Journal of Medicine (2005), 352(24):2487-2498.

9. Leon LM, Bailey B, Reifert J, Niemeyer C, Bendall H, Dauffenbach L et al. SDX-105 (Bendamustine), a clinically active antineoplastiv agent opsesses a unique mechanism of action. Blood (2003), 102(11):640.

10. Strumberg D, Harstrick A, Doll K, Hoffmann B, Seeber S. Bendamustine hydrochloride activity against doxorubicin-resistant human breast carcinoma cell lines. Anticancer Drugs (1996), 7(4):415-421.

11. Barman Balfour JA, Goa KL. Bendamustine. Drugs (2001), 61; 631-638(8).

12. Schrijvers D, Vermorken JB. Phase I studies with bendamustine: an update. Seminars in oncology (2002), 29 (4 Suppl. 13): 15-8.

13. Gandhi V. Metabolism and mechanisms of action of bendamustine: rationales for combination therapies. Seminars in oncology (2002), 29 (4 Suppl 13): 4-11

14. Forero-Torres A, Saleh MN. Bendamustine in NonHodgkin lymphoma: the double-agent that came from the cold war. Clinical lymphoma \& myeloma (2007), 8 (Suppl. 1): S13-7.

15. Rummel MJ et al. Bendamustine Plus Rituximab Versus CHOP Plus Rituximab in the First-Line Treatment of Patients with Indolent and Mantle Cell Lymphomas - First Interim Results of a Randomized Phase III Study of the StiL (Study Group Indolent Lymphomas, Germany). Blood (ASH Annual Meeting Abstracts) (2007), 110: 385. 
16. Friedberg JW, Cohen P, Chen L, Robinson KS, ForeroTorres A, La Casce AS, Favad LE, Bessudo A, Camacho ES, Williams ME, van der Jagz RH, Oliver JW, Cheson $\mathrm{BD}$. Bendamustine in patients with rituximab-refractory indolent and transformed non-Hodgkin's lymphoma: results from a phase II multicenter, single-agent study. Journal of Clinical Oncology (2008), 26(2):204-10.

17. Kahl B et al. Bendamustine Is Safe and Effective in Patients with Rituximab-Refractory, Indolent B-Cell NonHodgkin Lymphoma. Blood (ASH Annual Meeting Abstracts) (2007), 110: 1351.

18. Aivado M, Schulte K, Henze L, Burger J, Finke J, Haas R. Bendamustine in the treatment of chronic lymphocytic leukemia: results and future perspectives. Seminars in oncology (2002), 29 (4 Suppl 13): 19-22.

19. Cheson BD, Rummel MJ. Bendamustine: Rebirth of an old drug. Journal of Clinical Oncology (2009), 27(9): 1492-501.

20. Gaul L, Mandl-Weber S, Baumann P, Emmerich B, Schmidmaier R. Bendamustine induces G2 cell cycle arrest and apoptosis in myeloma cells: the role of ATMChk2-Cdc25A and ATM-p-53-p21-pathways. Journal of Cancer Research and Clinical Oncology (2008), 134 (2): 245-53.

21. Poenisch W, Niederwieser D. Bendamustine in the treatment of multiple myeloma: results and future perspectives. Seminars in oncology (2002), 29 (4 Suppl. 13): 23-6.

22. Lonial S. Multiple Myeloma: Noval approaches for relapsed disease. Clinical Lymphoma Myeloma (2007), 8 (Suppl. 1): 18-23.

23. Poenisch W, Mitrou PS, Merkle K, Herold M, Assmann M, Wilhelm G et al. Treatment of bendamustine and prednisone in patients with newly diagnosed multiple myeloma results in superior complete response rate, prolonged time to treatment failure and improved quality of life compared to treatment with melphalan and prednisone - a randomized phase III study of the East German study group of hematology and oncology (OSHO). Journal of Cancer Research and Clinical Oncology (2006), 132(4):205-212.

24. Knop S, Straka C, Haen M, Schwedes R, Hebart H, Einsele $\mathrm{H}$. The efficacy and toxicity of bendamustine in recurrent multiple myeloma after high-dose chemotherapy. Haematologica (2005), 90(9):1287-1288.

25. Poenisch W, Rozanski M, Goldschmidt H, Hoffmann FA, Boldt T, Schwarzer A, Ritter U, Rohrberg R, Schwalbe E, Uhlig J, Zehrfeld T, Schirmer V, Haas A, Kreibich U, Niederwieser D for the East German Study Group of Haematology and Oncology (OSHO). Combined bendamustine, prednisolone and thalidomide for refractory or relapsed multiple myeloma after autologous stem-cell transplantation or conventional chemotherapy: results of a Phase I clinical trial. British Journal of Hematology (2008), 143 (2): 191-200

26. Fenk R, Michael M, Zohren F, Graef T, Czibere A, Bruns I, Neumann F, Fenk B, Haas R, Kobbe G. Escalation therapy with bortezomib, dexamethasone and bendamustine for patients with relapsed or refractory multiple myeloma. Leukemia \& lymphoma (2007), 48 (12); 23452351.

27. Hrusivsky I, Heidtmann HH. Combination therapy of bortezomib with low-dose bendamustine in elderly patients with advanced multiple myeloma. Blodd (2005), ASH Annual Meeting Abstracts 106: Abstract 5122.
28. Blade J, Samson D, Reece D, Apperley J, Bjorkstrand B, Gahrton $G$ et al. Criteria for evaluating disease response and progression in patients with multiple myeloma treated by high-dose therapy and haematopoetic stem cell transplantation. Myeloma subcommittee of the EBMT. European Group for Blood and Marrow Transplant. British Journal of Haematology (1998), 102(5):1115-1123.

29. Attal M et al. The prognostic impact of complete remission (CR) plus very good partial remission (VGPR) in a double-transplantation program for newly diagnosed multiple myeloma (MM). Combined results ofthe IFM 99 trials. New England Journal Of Medicine (1996).

30. Lahuerta JJ, Mateos MV, Martínez-López J, Rosiñol L, Sureda A, de la Rubia J, García-Laraña J, MartínezMartínez R, Hernández-García MT, Carrera D, Besalduch J, de Arriba F, Ribera JM, Escoda L, Hernández-Ruiz B, García-Frade J, Rivas-González C, Alegre A, Bladé J, San Miguel JF. Influence of pre- and post-transplantation responses on outcome of patients with multiple myeloma: sequential improvement of response and achievement of complete response are associated with longer survival. Journal of Clinical Oncology (2008), 26 (35):5775-82

31. Jagannath S, Barlogie B, Berenson JR, Siegel DS, Irwin D, Richardson PG, Liesvizky R, Alexanian R, Limentani SA, Alsina M, Esseltine DL, Anderson KC. Updated survival analyses after prolonged follow-up of the phase 2, multicenter CREST study of bortezomib in relapsed or refractory multiple myeloma. British journal of haematology (2008); 143 (4): 537-40

32. Niesvizky R; Richardson PG; Rajkumar SV; Coleman M; Rosiñol L; Sonneveld P; Schuster MW; Irwin D; Stadtmauer EA; Facon T; Harousseau JL; Boral AL; Esseltine DL; Anderson KC; Bladé J. The relationship between quality of response and clinical benefit for patients treated on the bortezomib arm of the international, randomized, phase 3 APEX trial in relapsed multiple myeloma. British journal of haematology (2008); 143 (1): 6-53

33. Hussein MA, Baz R, Srkalovic G, Agrawal N, Suppiah R, Hsi E, Andresen S, Karam MA, Reed J, Faiman B, Kelly M, Walker E. Phase 2 study of pegylated liposomal doxorubicin, vincristine, decreased-frequency dexamethasone, and thalidomide in newly diagnosed and relapsedrefractory multiple myeloma. Mayo Clin Proc. (2006); 81(7): 889-95.4

34. Büssing A, Fischer J, Haller A, Heusser P, Ostermann T and Mathiessen PF. Validation of the brief multidimensional life satisfaction scale in patients with chronic diseases. European Journal of Medical Research (2009), 14(4):171-177

35. Büssing A, Girke M, Heckmann C, Schad F, Ostermann T, Kröz M. Validation of the self regulation questionnaire as a measure of health in quality of life research. European Journal of Medical Research (2009), 14(5): 223-227

Received: October 14, 2009 / Accepted: November 27, 2009

Address for correspondence:

PD Dr. med. Roland Fenk

Heinrich-Heine-Universität Düsseldorf

Klinik für Hämatologie, Onkologie und klinische Immunologie

Moorenstr. 5

40225 Düsseldorf

Tel.: $\quad+49-211-811-7760$

E-mail: fenk@med.uni-duesseldorf.de 